\title{
Traditional Culture and Modern Visual Communication Design Teaching
}

\author{
Hong Nie \\ School of Art and Design \\ Wuhan University of Science and Technology \\ Wuhan, Hubei, China
}

\begin{abstract}
Design is both art and the carrier of culture since its birth, and draws nourishment from the traditional culture. Up till now, design and traditional culture is still closely related. Visual communication realizes the delivery and communication of information through the generation and interpretation of the meaning of graphic images. This paper analyzes the application of philosophical thought, graphics, calligraphy, color and other elements of traditional culture in visual communication design, and explains how to combine the charm of traditional culture and modern design in modern visual communication design teaching, to achieve the inheritance and development of culture.
\end{abstract}

Keywords-traditional culture; Chinese calligraphy; religious culture; totem; auspicious patterns; modern visual communication design

\section{INTRODUCTION}

Design is a kind of concept and planning, as well as the process of visualizing such concept and planning through certain means. "The culture and art form features of a nation and an era are just the milestones of such historical changes, and the modeling style reflected by them are the inscription of the milestone." 1) Ancient China's aesthetic thoughts has provided theoretical basis for modern design. Starting from the Pre-Qin period, the unified classical aesthetics have been formed in China, and there is a complete set of special terms to represent the abstract cognitive content in aesthetic theories; In the times of "encouraging diverse thinking" after the Pre-Qin Period, the cultural pattern of coexistence of Confucianism, Buddhism and Taoism is basically formed due to the development of Taoism and Buddhism. In this period, it can be said the ancient Chinese culture is filled with the magnificent style of inclusiveness. While comparing the differences of Medieval Europe and Tang Dynasty of China, British scholar Wells wrote in Brief History of the World that: "When the westerners' soul is in the darkness confused by the theology, Chinese people's thoughts is open, inclusive and exploratory. "2) In addition to art, philosophy, religion, ethics and politics have greatly influenced the traditional culture of each dynasty.

Taoist advocates nature and soul perceiving. The surreal inaction thought and simple dialectic method have farreaching influence on traditional culture and artistic practice, and have formed a set of unique Chinese artistic dialectic

Funded Project: 2015 Teaching Reform Project of Hubei Province "Research and Practice on the curriculum system of visual communication design based on Chinese traditional culture" (item number 2015231). thought; the introduction of Buddhism has also enriched traditional Chinese culture, and there is a saying that Buddhism "comes from India, but succeeds in China". The thought of Zen has enriched the convocation of Chinese art works, improved the state of Chinese art, and even has got into such a situation that "do not read a poem if you don't understand Zen, do not discuss on painting if you don't understand Zen". In terms of artistic performance, classical aesthetics of traditional culture is not merely to pursue similarity in form, but to pursue similarity in spirit, and to pursue the spiritual qualities combining external things and subjective aesthetic ideal. We shall learn the aesthetic consciousness of traditional Chinese culture, so as to apply it in modern design skillfully.

\section{UNIQUE AND EXTRAORDINARY CHINESE CALLIGRAPHY}

In modern visual communication design, text is the main factor of modern design. However, Chinese calligraphy has become a unique art among the words in the world with its extraordinary pictographic conception and its unique charm. Chinese calligraphy can show people's aesthetic ideal, temperament, spirituality and personality more distinctively due to its styling and rich expressing objects compared with other types of art. The ancients even summed up it as "the writing is like the personality." Chinese ancient calligraphers enable us to feel the bone, tendons, flesh and blood in object images from feelings and emotions through the abstract point, line and stroke, just like that music and architecture can also appeal to our emotions, and to inspire human's life through our intuition. The modern calligraphy succeeds by virtue of strange and variant, which is eloquent, radiant and popular. Calligraphy has such kinds of functions as styling and expression, which need to be researched in-depth and grasped in our visual communication design.

Font design in visual communication design is no longer simply the interpretative language in the overall design, but the font itself is attached to the visual communication design as a design element, we can also regard it as a kind of visual language. Such visual language is essential in visual communication design, which not only conveys information in the form of text, but also forms strong visual appeal as a kind of graphic form. It has greater accuracy, advocacy and impact than the simple graphics, and its font selection and 
the design have played certain decisive role for the works. "Text design is the backbone of graphic design." 3) In the design teaching, students pursue sense of times blindly, and they are fond of the design of body text of character alphabet, with poor identification and lack of cultural connotation and personalized language, which cannot play a role in conveying information. In fact, in our traditional packaging, for example, the packaging design of both Shuanggou and Kong Fu Yan has referred to Chinese calligraphy, reflecting the products' history. The design has skillfully integrated Chinese wine culture and traditional calligraphy, highlighting the accumulation of traditional culture and the humanistic spirit. Besides, there is series packaging of folk ceramics, of which the main design picture is the two words of "Tu Tao" written in calligraphy, plus a red seal, which is substantial design. The vigorous font reminds people of the long history of this product, thus to trust the manufacturer, and generate the desire to buy, so as to promote sales.

If we choose to use calligraphy for design, we shall have a systematic understanding of calligraphy and combine the requirements for visual communication design, so as to digest it and use it skillfully. The 29th Olympic Games was held in Beijing in 2008. The emblem of it is Chinese seal, the dancing Beijing. The design of it has combined such art forms as traditional Chinese seal and calligraphy with the sport features, conveying and representing three layers of implications: First, take the seal of traditional Chinese culture as the pattern expression form of the main part of the logo, choose traditional color --- red as the reference color of the main part, reflecting the characteristics of Chinese culture, representing nation and the country as well as happiness and peace. Second, the main part of the works is like a Chinese character "Jing" and also like a dancing "person" with open arms, fully reflecting China with long history yet is full of sense of modern, conveying friendship, sincerity and passion. Third, the human figure running forward to meet the victory has fully reflected the Olympic purpose of faster, higher and stronger, stressed to regard sportsmen as the main body as well as the healthy and progressive spirit, being full of dynamism and vitality. This logo has expressed the Chinese culture and Olympic spirit incisively and vividly. President of the IOC, Rogge has also praised it, saying "it not only shows the history of China and the cultural heritage, but also conveys the spirit of a promising country full of youth and vigor." The combination of traditional culture and modern design is truly realized.

\section{Religious Traditional CUlture OF "BudDhism • TAOISM" BRINGING MYSTERIOUS COLOR}

As a social ideology, religion has been playing an important role in the history and reality in the development of human civilization. Therefore, if one cannot understand Western culture in-depth without knowing Christianity, similarly, one cannot actually understand traditional Chinese culture without understanding Confucianism, Taoism and Buddhism. From the process of Chinese ancient culture history, the ancient traditional culture and the religious thought of Confucianism, Taoism, Buddhism is manifested as a process of mutual penetration, mutual influence and interaction. Modern designers get deep inspiration from it, and it is bound to inspire the creation enthusiasm.

Dunhuang Grottoes of Buddhist Art has brought endless solemn mystery and beauty with the splendid frescoes; Buddhist sculpture is more wonderful vivid; the lofty state explains the original position of life thoroughly with farreaching and profound meaning. Among which, the various beautiful patterns also bring profound enlightenment to modern designers. Such a legacy can be found in the numerous excellent design works today, including fashion design.

As the oldest religion in China, Taoism advocates to respect for nature and spiritual contemplation. Its aesthetic thought of quiet, inaction, aura and void controls ancient Chinese aesthetic consciousness. The Eight Diagrams drawn by $\mathrm{Fu} \mathrm{Xi}$ is the prototype of Chinese characters; the Book of Changes written by King Wen is the beginning of Chinese culture. The surreal inaction thought has generated a farreaching influence on China's artistic development. For example, the origin of beauty generated from the treatment of Yin and Yang for the words on Pepsi can be found here. If we can comprehend the state of Taoism, and apply the magical generalization ability, imagination, as well as the rich colors and patterns reasonably into visual communication design teaching, a subtle influence will be generated on students, thus they can design extraordinary works, which will certainly bring a fresh air in the complex modern design. The beauty appreciation of religious culture not only caters to modern people's psychological needs, but also can bring the auspicious feeling to modern consumers, so as to achieve the purpose of conveying information.

\section{IV. "TOTEM" PATTERN WITH STRONG ETHNIC CHARACTERISTICS}

The Chinese ancestors have very extensive worship objects in primitive religions, and the objects can be divided into three categories such as nature worship, reproductionancestor worship and totemism. Totemism is a belief system of primitive nationalities. In the process of seeking survival, the ancient human deeply felt how tiny the human are, and how broad the universe is. The low level of productivity makes people unable to resist the nature that often rages. As a result, they formulate the totem belonging to their own tribe or ethnic group through imagination, and worship it extremely.

In the country with multiple nations, almost each nation has its own totem, which provides abundant material for our design teaching, inspiring our conception. And as for some symbols specifically used in the design, it can not only imply its origin and time, but also can give people a nostalgic and regressive meaning. Because these "totem" signs often appear in the scope of people's clothing, food, shelter, and transportation, people show a lot of love to it instinctively, looking like very intimate. And it is no longer the simple elements in design, but the language constituting modern visual communication, which is a natural expression of emotion. 
The folk traditional "Totem" ornamentation can bring a simple, fresh and interest flavor in modern visual communication design, whether it is used as the main part or as the shading, with a strong sense of decoration. The modern design works with the national characteristics and the sense of times can be designed by applying the folk traditional "totem" sign ornamentation having human kindness, in combination with the principle of modern visual communication design.

\section{PSYCHOLOGICAL IMPACT OF "FolK" Auspicious PATTERNS}

An auspicious pattern contains a beautiful myth, making people think deeply and yearn for it as emotions will generate upon our tough of objects. Our wise forefathers make the birds, animals, insects, flowers, fruits, grasses and woods in the nature into various patterns with auspicious meaning by homonyms of their names and metaphor. The artisans apply them to porcelain, lacquer, bronze, jade and painting, stone carving, embroidery, ornaments, etc., and its aesthetic value is very popular among people.

Pattern with auspicious meaning is part of our national traditional culture, with implicit connotation full of strength. Such concept will play an effective role in consumers' psychological needs if it is used in modern communication design. The "beauty" of auspicious patterns is highly concentrated, summarized, refined and subtle, having strength in implication, and it is meaning due to profundity.

\section{CONCLUSION}

Traditional culture is our nation's blood, and Chinese nation's inherent root growing in our heart. Over five thousand years' accumulation, Chinese nation has formed the cultural root full of features. Traditional culture represents our identity. Learning the modern contents does not mean to forget the past, and not to completely overturn or deny, otherwise, the gene of national culture will disappear. Regrettably, in the past century, we have lost too many things. We hope to repair and improve it through our continued efforts and re-develop the national culture.

"The deepest spiritual pursuit of Chinese nation is accumulated in Chinese culture, containing Chinese nation's most fundamental spiritual genes, representing Chinese nation's unique spiritual identity, which is the rich nourishment for Chinese nation's survival and development." 4) We shall develop traditional culture in cultural construction, to promote the harmonious development between human and nature as well as human and society with the national traditional culture, and this is also the inherent meaning of harmonious society.

\section{REFERENCES}

[1] Liu Guanzhong. “design methodology”. Higher Education Press; 2011.

[2] Zhang Dainian, Fang Keli. "an introduction to chinese culture". Beijing Normal University Press; 1994.

[3] Asixo. "Korean design 1". Hunan Fine Arts Publishing House; 2007
[4] On November 26, 2013, General Secretary Xi Jinping's speech with visiting study Confucian, Confucius Institute in Qufu, Shandong 